\title{
Electromyographic and Cardiorespiratory Responses of Load Carriage at Different High Altitudes with Varying Gradients
}

\author{
Tirthankar Chatterjee, ${ }^{1,}$ Debojyoti Bhattacharyya, ${ }^{1}$ Anilendu Pramanik, ${ }^{1}$ Madhu Sudan Pal, ${ }^{1}$ and \\ Dhurjati Majumdar ${ }^{2}$ \\ ${ }^{1}$ Defence Institute of Physiology and Allied Sciences, Defence Research and Development Organisation, Min. of Defence, Govt. of India, Lucknow Road, Delhi-110054, India \\ ${ }^{2}$ Retired from: Institute of Nuclear Medicine and Allied Sciences, Defence Research and Development Organisation, Min. of Defence, Govt. of India, Lucknow Road, \\ Delhi-110054, India
}

"Corresponding author: Tirthankar Chatterjee, MSc, Scientist 'C', Defence Institute of Physiology and Allied Sciences, Defence Research and Development Organisation, Min. of Defence, Govt. of India, Lucknow Road, Delhi-110054, India. Tel: +91-1123883012, Fax: +91-1123914790, E-mail: tchatterjee@dipas.drdo.in

Received 2017 January 27; Revised 2017 February 09; Accepted 2017 February 09.

\begin{abstract}
Manual load carriage is performed by Indian Army soldiers at different high altitudes (HA) in day to day operation. Such task puts extra stress on cardiorespiratory and skeletomuscular systems. A study was designed to find out the effect of electromyographic and cardiorespiratory responses of load carriage at different high altitudes with varying gradients. Eight healthy Indian infantrymen (mean ( \pm SD) age of $27.2( \pm 3.9)$ years, height of $171.1( \pm 2.5) \mathrm{cm}$, and weight of $66.8( \pm 6.7) \mathrm{kg}$ ) participated in the study. They were acclimatized at two heights ( 3550 and $4300 \mathrm{~m}$ ). On completion of their acclimatization each participant was checked for healthy cardiorespiratory signs and subsequently they walked on a motorized treadmill at a speed of $3.5 \mathrm{~km}^{-\mathrm{hr}^{-1}}$ and $0 \%$ and $10 \%$ gradients under three different experimental load carrying conditions (0,10.7 and $21.4 \mathrm{~kg}$ ). Continuous electromyography of three pairs of leg muscles i.e. vastus medialis, gastrocnemius, and tebialis anterior and breath-by-breath recording of oxygen consumption $\left(\mathrm{VO}_{2}\right)$ and heart rate (HR) were recorded during the experiments. Relative work load (RWL) was calculated from maximum aerobic capacity at respective high altitudes. High altitude had significant effects on the responses of gastrocnemius and vastus medialis muscles as well as on $\mathrm{VO}_{2}$ and $\mathrm{RWL}$. Increased responses of $\mathrm{VO}_{2}$ and leg muscle could be attributed to withstanding the stress of HA and strain of load carriage at steep slopes.
\end{abstract}

Keywords: Load Carriage, Electromyography, Leg Muscles, Heart Rate, High Altitudes

\section{Background}

Indian soldiers are compelled to carry load manually as wilderness of the high altitude terrains construct a critical barrier to the vehicular mode of transportation of load (1). Indian Army deploys more than hundred thousand soldiers in the high altitude border areas. The soldiers have to be well equipped and physically fit to guard the nation's border. The equipment is generally heavy and is carried in a rough terrain with steep paths (up to $25 \%$ gradient) of high altitude. The maximum freedom of mobility gets the ultimate importance in modern warfare scenario; thus, the soldier must be optimally loaded. On the other hand, loads are distributed in waist, back, shoulders, and in the hands for a marching order in Indian Army (2). The composite load in existing load carriage ensembles (LCe) amounts to $21.4 \mathrm{~kg}$ consisted of a backpack (BP, $10.7 \mathrm{~kg}$ ), a haversack (HS, $4.4 \mathrm{~kg}$ ), and an web (2.1 kg) distributed in the back and waist side of body and INSAS rifle $(4.2 \mathrm{~kg})$ in hand (3).

Harman et al. (2000) (4) addressed that load carriage tasks put stress on the musculoskeletal system of the car- rier. Carrying a load may increase lower limb loading, which places high stress on the soft tissues surrounding the leg joints (5), predisposing the participant to the risk of injuries as well as stress fractures, and brachial plexus palsy (6-8). Increase in electromyographic (EMG) amplitude is known to have positive correlation with increasing muscular force $(9,10)$. Increased EMG activity with increase in load has been reported for gastrocnemius, hamstring, and quadriceps muscles (11). Effects of acute, prolonged hypoxia (during simulated ascent) on performance and contractile properties of human skeletal muscle were evaluated by Perry and Rupp (2009) (12). They found that sustained isometric exercise exceeding $30 \%$ of maximum voluntary contraction (MVC) which caused substantial and sustained ischemia was not affected by acute hypoxia. Similar observation was cited by Orizio et al. (1993) (13) and Esposito et al. (2003) (14) who recorded EMG activity during isometric contraction and found acute or chronic hypoxia did not affect the maximal force output or fast to slow fibre motor unit (MU) ratio and MU activation pattern. In an experiment including 32-day simulated ascent

Copyright @ 2017, AJA University of Medical Sciences. This is an open-access article distributed under the terms of the Creative Commons Attribution-NonCommercial 4.0 International License (http://creativecommons.org/licenses/by-nc/4.0/) which permits copy and redistribute the material just in noncommercial usages, provided the original work is properly cited. 
of Mount Everest (8848 m) (Everest III Comex '97), effects of re-oxygenation on muscle function were assessed. The authors found that prolonged exposure to hypoxia slowed the propagation of myopotentials and alters sensorimotor control during sustained effort (15).

Soldiers are frequent visitors to high altitude (HA) areas for their occupational need. As per requirement, they have to carry moderate to heavy loads in these areas. Thus, proper evaluation of skeleto-muscular and physiological system during load carriage task at HA location is very important. A guideline on how to condition military personnel for load carriage tasks in the field locations (i.e. HA) and optimum weight of the equipment at specific height is also lacking in literature. Continuous monitoring of physiological and muscular responses at HA during load carriage task with and without graded walking would be relevant in this context. Hence, a study was designed with Indian Army soldiers to investigate their cardiorespiratory and electromyographic changes during load carriage with varying gradients at two HAs. The study also aimed to develop some guidelines for load carriage at HA with inclination based on relative workload.

\section{Methods}

\subsection{Participants}

Eight Indian infantry soldiers with mean ( \pm SD) age of 27.2 ( \pm 3.9 ) years, height of $171.1( \pm 2.5) \mathrm{cm}$, and weight of 66.8 ( \pm 6.7$) \mathrm{kg}$ took part in the study as volunteers. The participating soldiers were selected randomly for the study. The volunteers were low land natives of India and were on the way of their first HA posting. The participants who came under Shape-I category of Indian Army were included in the study. Participants with any prior medical (cardiorespiratory) history or occurrence of musculoskeletal injuries were excluded from the study. Physical characteristics of the soldiers are presented in Table 1. The volunteers were proscribed from smoking and alcohol consumption throughout the study period. They were allowed to carry out jogging and light exercise in the morning; also, they had been relieved from night duty during the course of experiment.

\subsection{Ethical Clearance}

A clearance from the ethical committee of the author's institute, which conforms to the recommendations of the declaration of Helsinki (1983), was obtained prior to the study. Thereafter, soldiers were briefed about the purpose and the risk of the experimentation and their informed consent was obtained consequently.
Table 1. Physical Characteristics of the Volunteers

\begin{tabular}{|c|c|}
\hline Parameters & Mean \pm SD \\
\hline Age, $y$ & $26.2 \pm 3.9$ \\
\hline Height, cm & $171.1 \pm 2.9$ \\
\hline Weight, kg & $66.8 \pm 6.8$ \\
\hline \multicolumn{2}{|c|}{$\mathrm{VO}_{2 \max }, \mathrm{mL} \cdot \mathrm{min}^{-1} \cdot \mathrm{kg}^{-1}$} \\
\hline HA1 & $44.9 \pm 6.3$ \\
\hline HA2 & $37.0 \pm 3.9$ \\
\hline
\end{tabular}

\subsection{High Altitude Acclimatization}

At HAs, the participants followed the standard acclimatization schedule of Indian Army as per Army order (16). At the first HA location, i.e. Leh (3505 m, HA1), an acclimatization period of initial 6 days of arrival was strictly followed. On 1st and 2nd days: resting, except for short walk; on 3rd and 4th days: walking at slow pace at 1.5 to $3 \mathrm{~km} . \mathrm{hr}^{-1}$; and on 5th and 6th days: walking up to $5 \mathrm{~km}$ and climbing up to $300 \mathrm{~m}$ at a slow pace were allowed. Symptoms of acute mountain sickness were monitored throughout the period by medical staff. At the second HA, (Tangtse 4300 $\mathrm{m}, \mathrm{HA} 2$ ) the acclimatization period was reduced to 4 days as per Army order. On 1st and 2nd days: slow walking for a distance at 1.5 to $3 \mathrm{~km} . \mathrm{hr}^{-1}$ without any steep climbs; on 3rd day: slow walking and climbing up to $300 \mathrm{~m}$; and on 4th day: climbing $300 \mathrm{~m}$ without equipment were allowed. The participants were declared medically fit by a qualified medical doctor with experience in high altitude medicine.

\subsection{Load Carriage Experiments}

The volunteers were first accustomed with walking on a motorized treadmill $(\mathrm{h} / \mathrm{p} /$ cosmos treadmill, Cortex Biophyzik Ltd, Leipzig, Germany) with different speeds and gradients. The participants walked on the treadmill for load carriage experiment at HA1 and HA2 with two magnitudes of load i.e. $10.7 \mathrm{~kg}$ (L1- Haversack (HS), Web and Rifle), 21.4 kg (L2- Backpack (BP), HS, Web and Rifle), and without load (No load, NL) at two gradients (0 and 10\%) for 10 minutes. A 10 minutes duration was selected for the experiment in view of the fact that physiological systems take few minutes to get stabilized during continuous activity of same intensity. This phenomenon has been observed by the authors in their previous studies with similar experimental set up $(3,16,17)$. During the experiments, walking speed was fixed at $3.5 \mathrm{~km} . \mathrm{hr}^{-1}$ considering the suggestions on optimum speed at HA by previous researchers (i.e. 3 - $3.5 \mathrm{~km} . \mathrm{hr}^{-1}$ ) and keeping in mind the associated difficulties of load carriage under hypoxic conditions (17, 18). Modes, magnitude, and the percentage of body weight 
and placement of the loads are briefed in Table 2. The load carriage experiments were randomized. The experiments were carried out in the temporary laboratory setup at both the study locations. The volunteers wore vest, shorts, and boot during the load carriage experiments for ease of electrode placement.

Table 2. Percentage of Body Weight with Magnitude, Different Components, and Placement of Loads

\begin{tabular}{lccc}
\hline Mode & Weight & Components & \% of Body Weight \\
\hline $\begin{array}{l}\text { Existing load } \\
\text { carriage } \\
\text { ensemble of } \\
\text { Indian Army }\end{array}$ & $10.7 \mathrm{~kg}$ & $\begin{array}{c}\text { Haver sack(HS)-in } \\
\text { the waist, Web } \\
\text { (WB)- in front waist } \\
\text { region, Rifle- hand }\end{array}$ & 16.2 \\
\hline Same as above & $21.4 \mathrm{~kg}$ & $\begin{array}{c}\text { Back pack(BP)- } \\
\text { back, HS, Wb, Rifle }\end{array}$ & 32.3 \\
\hline
\end{tabular}

\subsection{Measurement of Maximal Aerobic Capacity}

The maximum oxygen consumption $\left(\mathrm{VO}_{2 \max }\right)$ was measured during treadmill exercise with regular increase in the gradient while keeping the speed constant (Harbor protocol) (19). During the measurement of $\mathrm{VO}_{2 \max }$, participants wore vest, underwear, shorts, and physical training shoes. They were allowed to take rest for one hour before the beginning of the experiment. During the experiments, heart rate (HR) and oxygen consumption $\left(\mathrm{VO}_{2}\right)$ of each individual were recorded by the process of breath-by-breath gas analysis using Meta-max 3B system (MMX 3B, Cortex, Germany). This protocol was performed at two high altitude locations.

\subsection{Recording of Physiological and Subjective Data}

Participants' oxygen saturation $\left(\mathrm{SpO}_{2}\right)$ and HR were monitored by fingertip pulse oximeter (ChoiceMMed Technologies, India) throughout acclimatization period and before and after the completion of each experiment. Physiological parameters such as $\mathrm{VO}_{2}$ and $\mathrm{HR}$ were recorded by using MMX 3B breath-by-breath gas analysis system. The relative work load ( $\left.\mathrm{RWL}, \% \mathrm{VO}_{2 \max }\right)$ was calculated as percentage of $\mathrm{VO}_{2 \max }$ at respective altitudes. The MMX 3B system was thoroughly calibrated for volume with standard 3 Lt volume syringe, standard gas mixture, pressure, and ambient air before start of the experiments. The validity, reliability, and stability of MMX 3B gas analysis system were verified in a combination of tasks similar to the present study (20). Room air temperature and relative humidity (RH) were monitored by a digital thermometerhygrometer. Necessary information for ambient air pressure (Barometric pressure, Pr) was obtained from Indian air-force station at HA1 and environment monitoring centre at HA2. Changes in atmospheric pressure and relative humidity are presented in Table 3. The same experimental protocol was followed at both the altitudes. After each experiment, the participants rated their perceived exertion on a 14-point rating of perceived exertion (RPE) sheet (Borg's 6 - 20 scale) (21). The average values of the last 3 minutes of the physiological parameters mentioned above were considered for statistical treatment.

Table 3. Changes in Temperature, Relative Humidity, Barometric Pressure in Two High Altitudes

\begin{tabular}{lccc}
\hline Altitudes & Temperature, ${ }^{\circ} \mathrm{C}$ & $\mathbf{R H}, \%$ & Pr, mm.Hg \\
\hline HA1 & $22-28$ & $18-35$ & 511 \\
HA2 & $16.5-21.5$ & $35-60$ & 441 \\
\hline
\end{tabular}

Abbreviations: RH, relative humidity; Pr, pressure.

\subsection{Recording of Electromyography}

Simultaneous to the physiological data collection, electromyographic recording was carried out throughout the experimentation on three groups of lower limb muscles including left and right Gastrocnemius medialis (GMR and GML), Tibialis anterior (TAR and TAL), and Vastus medialis (VMR and VML) muscles. The muscles of shoulder and back are rigorously used during load carriage with backpack (22). These muscles were not used in the study because the placement of EMG electrodes would require bare body experimentation, which would be difficult in the cold conditions of HA. On the other hand, leg muscles are also extensively used in walking and climbing (23). Hence, these muscles were taken for the study. Delsys Myomonitor (4.0) system along with pre-amplified electrodes $(n=6)$ and EMGworks 4.0 recording software were used to record electromyographic signals (frequency-1024 Hz). Active bipolar pre-amplified electrodes (Delsys) were aligned along the fibres of the muscle under investigation according to the recommendations by SENIAM (24). Prior to electrode placement, each site was shaved, cleansed with alcohol, and gently abraded. In order to reduce cable movement artefact, cables were secured using elastic bands (25). EMGworks 4.0 analysis software was used to analyze the recorded data. First, the 'Raw EMG' signal plot was created; then, root mean square (RMS) value was computed on analysis software platform; finally, the data were exported to Microsoft Excel format and taken for final analysis. The acquisition, analyses, and representation of EMG data collected from isometric and ballistic contractions by Delsys Myomonitor (4.0) system were found reliable in an earlier study (26). Figures 1 and 2 show physiological and EMG data collection during load carriage task at HA1 with L2 at 0 and 10\% gradients. 


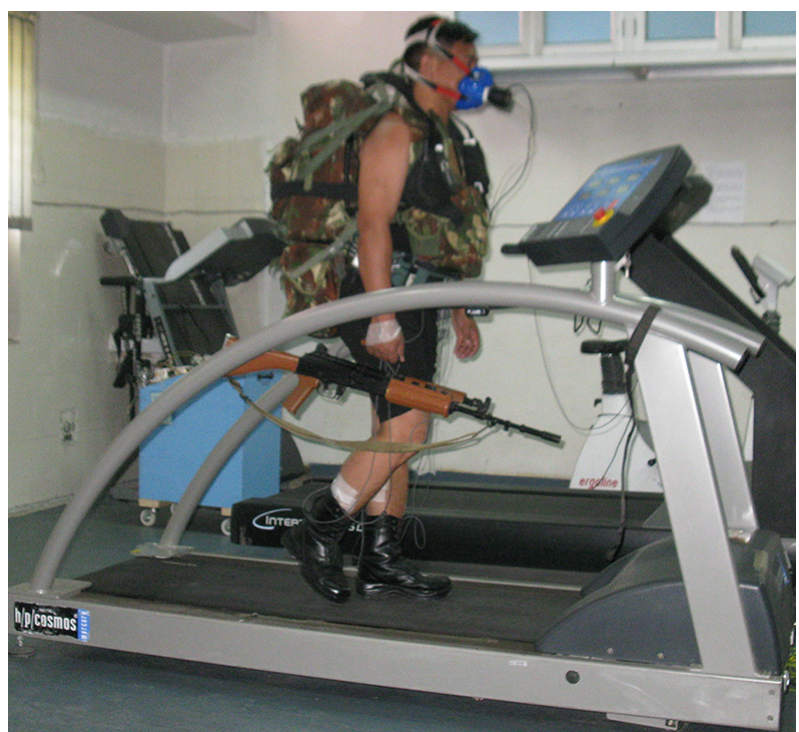

Figure 1. Physiological and EMG Data Collection During Load Carriage Task at $0 \%$ at HA1

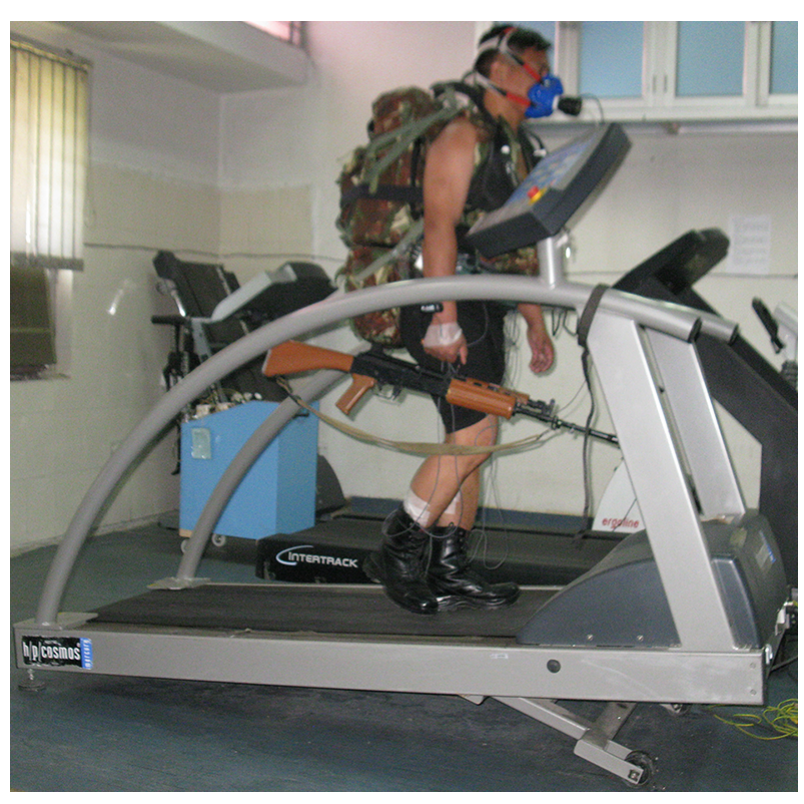

Figure 2. Physiological and EMG Data Collection During Load Carriage Task at 10\% at HA1

\subsection{Normalization}

Normalization of the RMS values was performed by calculating the percentage of RMS data obtained by doing maximum voluntary contraction (MVC) of the same muscle $(27,28)$. At least, 3 repetitions of the test were performed, which were separated by taking rest for more than
3 minutes to reduce any fatigue effects (29). Slight warming up exercises were performed (including stretching and low intensity aerobic exercises) before increasing the force of contraction during the protocol and keeping it for 3 - 5 seconds and then relaxing. MVC was taken at the two HAs. The participants were asked to perform unilateral plantar flexion at $90^{\circ}$ of the ankle position for MVC of gastrocnemius. The participants were also asked to perform dorsiflexion in supine position against the force applied for tibialis anterior. They were required to stay in sitting position and extend the leg at $90^{\circ}$ against the force for vastus medialis. The signal was processed as mentioned above. RMS was calculated with the EMGworks analysis software. Then, average of the RMS of the MVC was calculated in excel format and used for normalization. The mean of the last two minutes of RMS values of each muscle during each load carriage experiment was used for normalization. The same experimental protocol was followed at HA1 and HA2.

\subsection{Statistical Analysis}

Before going for statistical treatment, the data set was tested for skewness and normality by using Shapiro-Wilk test as the sample size was less than 50. A three way repeated measures ANOVA was applied for the physiological parameters as the same group of volunteers was exposed to two levels of altitudes, two levels of gradients, and three levels of loads to see over all significance across the conditions. The degree of freedom (df) of the data was checked through Mauchly's test of sphericity for all independent variables and their combinations. The respective ' $F$ ' values were taken to check the level of significance. If the sphericity is not assumed, then it was corrected with Greenhouse Geisser's correction factor. The corresponding 'F' values were taken as the level of significance. Subsequent to the observed significance level for the various cardiorespiratory and electromyographic parameters, Bonferroni PostHoc test was applied to compare between the conditions pairwisely. For all the tests, statistical significance was verified at $\mathrm{P} \leq 0.05$ level. Statistical analysis was performed using SPSS, version 16.0 (IBM Corporation, New York, USA).

\section{Results}

\subsection{Physiological and Subjective Parameters}

The $\mathrm{SpO}_{2}$ of the participants in the present study stabilized at around $92 \%$ at HA1 and around 91\% at HA2 at rest. The average $\mathrm{VO}_{2 \max }$ at two HAs was $44( \pm 5.7)$ and 37.3 ( \pm 4.0), respectively (Table1). Changes in HR with different levels of gradients, loads, and altitudes are presented in Figure 3. Repeated measures ANOVA revealed that HR significantly increased with the following conditions; gradient: 
$F(1,7)=161.379$ and load: $F(2,14)=72.897(P<0.05)$. HR had a significant increase with the interaction of gradient and altitude: $F(1,7)=19.567$, gradient and load: $F(2,14)=$ 4.526, and gradient, load, and altitude: $F(2,14)=4.125(P$ $<0.05)$. Pairwise comparison by Bonferroni test revealed a significant difference between the effects of two levels of gradient and the effects of three levels of load. Oxygen consumption responses with different gradients, loads, and altitudes are presented in Figure 4. From the results of repeated measures ANOVA, the $\mathrm{VO}_{2}$ showed a significant increase with the following conditions; gradient: $F(1,7)=$ 78.948, altitude: $F(1,7)=8.267$, and load: $F(2,14)=154.386$ $(\mathrm{P}<0.05) . \mathrm{VO}_{2}$ also changed significantly with the following interactions; gradient and load: $F(2,14)=28.358$, altitude and load: $F(1,7)=10.934$, gradient, altitude, and load: $F(2,14)=15.850(P<0.05)$. Post-Hoc test showed a significant difference between the effects of both levels of gradient, both levels of altitude, and all three levels of load. Changes in RWL with different gradients, loads, and altitudes are presented in Figure 5. RWL showed a significant increase with the following conditions; gradient: $F(1,7)=$ 114.101, altitude: $F(1,7)=52.199$, and load: $F(2,14)=171.221$ $(\mathrm{P}<0.05)$. RWL also changed significantly with the interactions of gradient and load: $F(2,14)=38.161$, altitude and load: $F(1,7)=11.637$, gradient, altitude, and load: $F(2,14)$ $=10.875(\mathrm{P}<0.05)$. Post-Hoc test revealed a significant difference between the effects of both levels of gradient, both levels of altitude, and all three levels of load. Perceived exertions changed with different gradients, loads, and altitudes as presented in Figure 6. Repeated measures ANOVA revealed that RPE had a significant increase with the following conditions; gradient: $\mathrm{F}(1,7)=39.625$, load: $\mathrm{F}(1.256$, $8.795)=101.984,(P<0.05)$. RPE had a significant increase with the interaction of gradient and load: $\mathrm{F}(2,14)=4.704$, altitude and load: $\mathrm{F}(2,14)=7.432(\mathrm{P}<0.05)$. Bonferroni pairwise comparison test revealed a significant difference between the effects of $0 \%$ and $10 \%$ of gradient as well as all three levels of load.

\subsection{Electromyographic Parameters}

Changes in VMR activity with different gradients, loads, and altitudes are presented in Figure 7. The activation of VMR showed a significant increase with the following conditions; gradient: $F(1,7)=24.517$ and load: $F(2,14)$ $=7.118(\mathrm{P}<0.05)$. VMR also changed significantly with the interaction of gradient and altitude: $F(1,7)=7.804(\mathrm{P}<$ 0.05). Pairwise comparison found a significant difference between the effects of both levels of gradients, and the levels of 0 and $21.4 \mathrm{~kg}$ of load. VML response with different gradients, loads, and altitudes are presented in Figure 8. A significant increase was observed in VML activity with gradient: $F(1,7)=82.440$ and load: $F(2,14)=10.111(P<0.05)$. Pair- wise comparison revealed a significant difference between the effects of gradient levels of 0 and $10 \%$ and load levels of 0 and $21.4 \mathrm{~kg}$. Changes in TAR activity with different gradients, loads, and altitudes are presented in Figure 9. At HA1, the response of TAR increased with load and gradient. The activities of TAR did not increase with gradient but changed with load. These changes were not statistically significant. TAL response with different gradients, loads, and altitudes is presented in Figure 10. The response of TAL showed a significant increase with load: $F(2,14)=4.757$ ( $P$ $<0.05$ ). Activity of Gastrocnemius right with different gradients, loads, and altitudes is presented in figure 11. Overall, a significant increase was seen in GMR activity with following conditions; gradient: $F(1,7)=22.677$ and load: $F$ $(2,14)=10.945(\mathrm{P}<0.05)$. Bonferroni pairwise comparison revealed a significant difference between the effects of $0 \%$ and $10 \%$ gradients and 0 and $21.4 \mathrm{~kg}$ loads. Changes in GML activity with different gradients, loads, and altitudes are presented in Figure 12. The activity of GML increased significantly with the following conditions; gradient: $\mathrm{F}$ (1, $7)=15.322$ and load: $F(2,14)=16.596(P<0.05)$. Pairwise comparison by Bonferroni Post-Hoc test showed a significant difference between the effects of both levels of gradients, two levels of 0 and $21.4 \mathrm{~kg}$ load, as well as two levels of $10.7 \mathrm{~kg}$ and $21.4 \mathrm{~kg}$ load. The effects of HA and gradient which were significant based on Post-Hoc test on various physiological, subjective, and electromyographic parameters in terms of percentage increases are presented in Tables 4 and 5. The responses of TAR and TAL are not included in the tables as these muscles were not affected by HA and gradient factors.

\section{Discussion}

In the present study, the physiological parameters like $\mathrm{VO}_{2}$ and RWL significantly increased with increasing load, gradient, and altitude. HR and RPE of the participants increased significantly with load and gradient. On the other hand, the $\mathrm{SpO}_{2}$ status at two HAs indicated insufficient oxygenation of blood within the lung. Physiological and mechanical factors affecting walking and running extreme uphill and downhill gradients were evaluated by Minetti et al. (2002) (30). They observed that energy cost of walking and running increased with increment of gradient. The authors explained this elevated energy expenditure as a 'safety factor' to minimize tissue and joint injury. Studies by Crouter et al. (2001) (31) and Padulo et al. (2013) (32) supported this observation. Nag et al. (1978), (18) studied load carriage up to $55 \mathrm{~kg}$ on Nepalese porters at HA in steep mountainous paths and found increased $\mathrm{VO}_{2}$. Extreme muscular fatigue and longer recovery time of the 


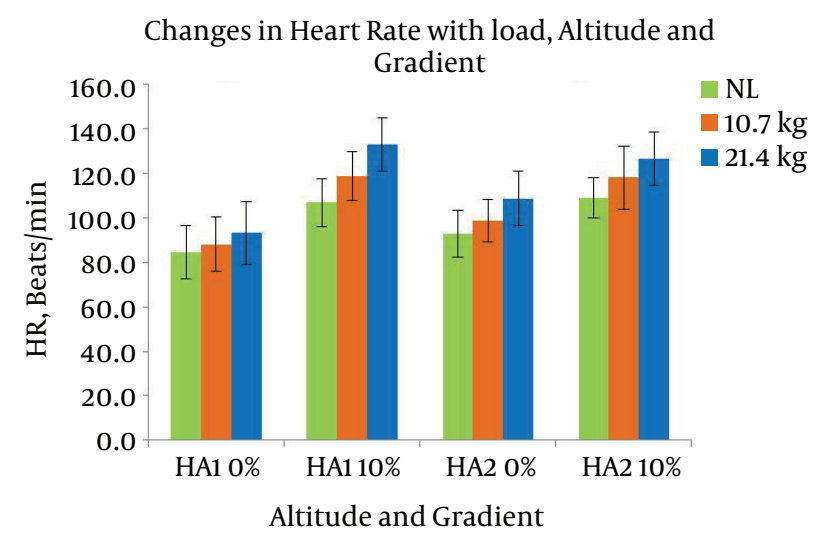

Figure 3. Changes in HR with Altitude, Load, and Gradient

Table 4. Effect of High Altitude on Various Parameters Across Three Loads and Two Altitudes in Terms of Percentage Variations

\begin{tabular}{|c|c|c|c|c|c|c|c|c|}
\hline \multirow{2}{*}{$\begin{array}{l}\text { Gradient } \\
\text { Muscles }\end{array}$} & \multicolumn{3}{|c|}{$\mathbf{0} \%$} & \multicolumn{5}{|c|}{$10 \%$} \\
\hline & NLHA1 V L1HA1 & NLHA1 V L2HA1 & NLHA2 V L1HA2 & $\begin{array}{l}\text { NLHA2 V } \\
\text { L2HA2 }\end{array}$ & NLHA1 V L1HA1 & NLHA1 V L2HA1 & NLHA2 V L1HA2 & $\begin{array}{c}\text { NLHA2 V } \\
\text { L2HA2 }\end{array}$ \\
\hline HR & $4^{\mathrm{a}}$ & $10^{\mathrm{a}}$ & $6^{\mathrm{a}}$ & $17^{\mathrm{a}}$ & $11^{\mathrm{a}}$ & $25^{\mathrm{a}}$ & $8^{\mathrm{a}}$ & $16^{\mathrm{a}}$ \\
\hline $\mathrm{VO}_{2}$ & $16^{\mathrm{a}}$ & $22^{\mathrm{a}}$ & $17^{\mathrm{a}}$ & $10^{\mathrm{a}}$ & $35^{\mathrm{a}}$ & $75^{\mathrm{a}}$ & $15^{\mathrm{a}}$ & $25^{\mathrm{a}}$ \\
\hline RWL & $10^{\mathrm{a}}$ & $23^{\mathrm{a}}$ & $6^{\mathrm{a}}$ & $17^{\mathrm{a}}$ & $33^{\mathrm{a}}$ & $74^{\mathrm{a}}$ & $15^{\mathrm{a}}$ & $25^{\mathrm{a}}$ \\
\hline RPE & $10^{\mathrm{a}}$ & $35^{\mathrm{a}}$ & $21^{a}$ & $53^{\mathrm{a}}$ & $24^{\mathrm{a}}$ & $44^{\mathrm{a}}$ & $39^{\mathrm{a}}$ & $63^{a}$ \\
\hline VMR & 14 & $20^{\mathrm{a}}$ & 25 & $33^{\mathrm{a}}$ & 11 & $37^{\mathrm{a}}$ & 24 & $40^{\mathrm{a}}$ \\
\hline VML & 17 & $20^{\mathrm{a}}$ & 26 & $31^{\mathrm{a}}$ & 10 & $32^{\mathrm{a}}$ & 22 & $36^{\mathrm{a}}$ \\
\hline GMR & 5 & $33^{\mathrm{a}}$ & 4 & $29^{\mathrm{a}}$ & 16 & $22^{\mathrm{a}}$ & 23 & $27^{\mathrm{a}}$ \\
\hline GML & 2 & $27^{\mathrm{a}}$ & 12 & $35^{\mathrm{a}}$ & 13 & $42^{\mathrm{a}}$ & 6 & $21^{\mathrm{a}}$ \\
\hline
\end{tabular}

Abbreviations: HA1, high altitude 1; HA2, high altitude 2; NL, without load; L1, 10.7 kg; L2, 21.4 kg.

${ }^{a}$ Significant after computing pairwise comparison, $\mathrm{P}<0.05$.

Table 5. Effect of Gradient on Various Parameters Across Three Loads and Two Gradients in Terms of Percentage Variations

\begin{tabular}{|c|c|c|c|c|c|c|}
\hline \multirow{2}{*}{$\begin{array}{l}\text { +Altitude } \\
\text { Muscles }\end{array}$} & \multicolumn{3}{|c|}{ HA1 } & \multicolumn{3}{|c|}{ HA2 } \\
\hline & NLG1 V NLG2 & L1G1 V L1G2 & L2G1 V L2G2 & NLG1 V NLG2 & L1G1 V L1G2 & L2G1 V L2G2 \\
\hline HR & $26 a$ & $35^{\mathrm{a}}$ & $43^{\mathrm{a}}$ & $18^{\mathrm{a}}$ & $20^{\mathrm{a}}$ & $17^{\mathrm{a}}$ \\
\hline $\mathrm{vo}_{2}$ & $30^{\mathrm{a}}$ & $51^{\mathrm{a}}$ & $87^{\mathrm{a}}$ & $33^{\mathrm{a}}$ & $34^{\mathrm{a}}$ & $32^{\mathrm{a}}$ \\
\hline RWL & $37^{\mathrm{a}}$ & $67^{\mathrm{a}}$ & $94^{\mathrm{a}}$ & $54^{\mathrm{a}}$ & $58^{\mathrm{a}}$ & $59^{\mathrm{a}}$ \\
\hline VMR & $65^{\mathrm{a}}$ & $34^{\mathrm{a}}$ & $89^{\mathrm{a}}$ & $23^{\mathrm{a}}$ & $23^{\mathrm{a}}$ & $29^{\mathrm{a}}$ \\
\hline VML & $42^{\mathrm{a}}$ & $34^{\mathrm{a}}$ & $56^{\mathrm{a}}$ & $56^{\mathrm{a}}$ & $51^{a}$ & $62^{a}$ \\
\hline GMR & $35^{\mathrm{a}}$ & $49^{\mathrm{a}}$ & $23^{\mathrm{a}}$ & $18^{\mathrm{a}}$ & $39^{\mathrm{a}}$ & $16^{\mathrm{a}}$ \\
\hline GML & $20^{\mathrm{a}}$ & $34^{\mathrm{a}}$ & $35^{\mathrm{a}}$ & $23^{\mathrm{a}}$ & $16^{\mathrm{a}}$ & $10^{\mathrm{a}}$ \\
\hline
\end{tabular}

Abbreviations: G1, 0\%; G2, 10\%HA1; high altitude 1; HA2, high altitude 2; NL, without load; L1, $10.7 \mathrm{~kg}$; L2, 21.4 kg.

${ }^{\mathrm{a}}$ Significant after computing pairwise comparison, $\mathrm{P}<0.05$. 


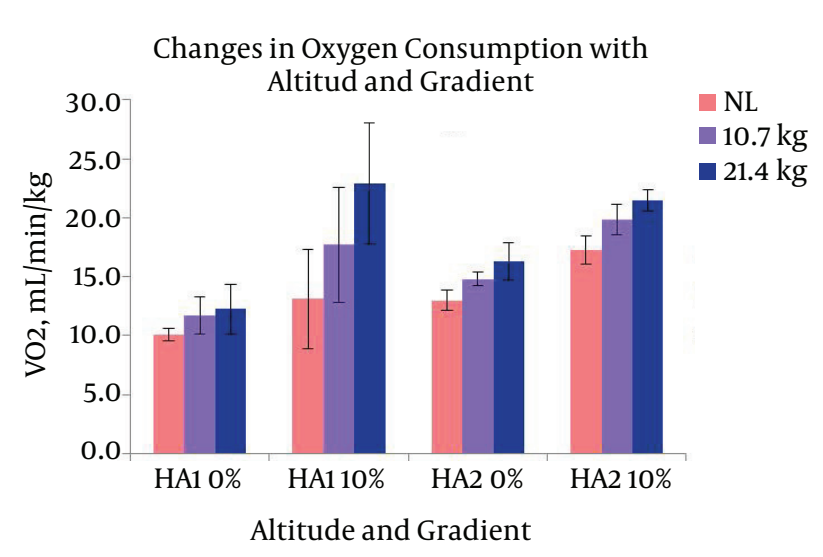

Figure 4. Changes in $\mathrm{VO}_{2}$ with Altitude, Load, and Gradient

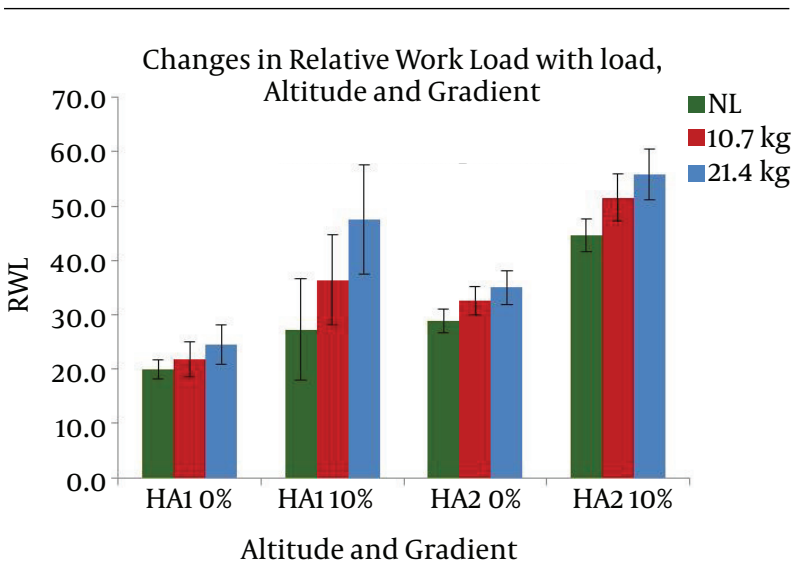

Figure 5. Changes in RWL with Altitude, Load, and Gradient

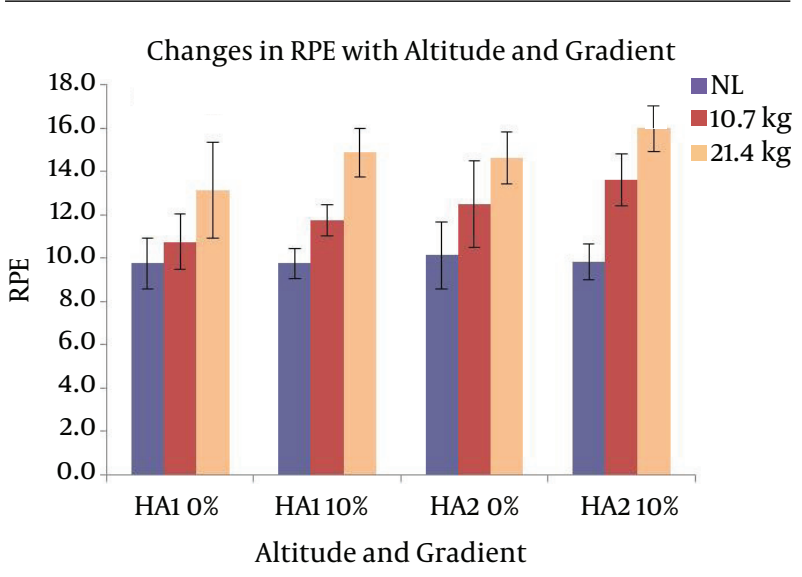

Figure 6. Changes in RPE with Altitude, Load, and Gradient

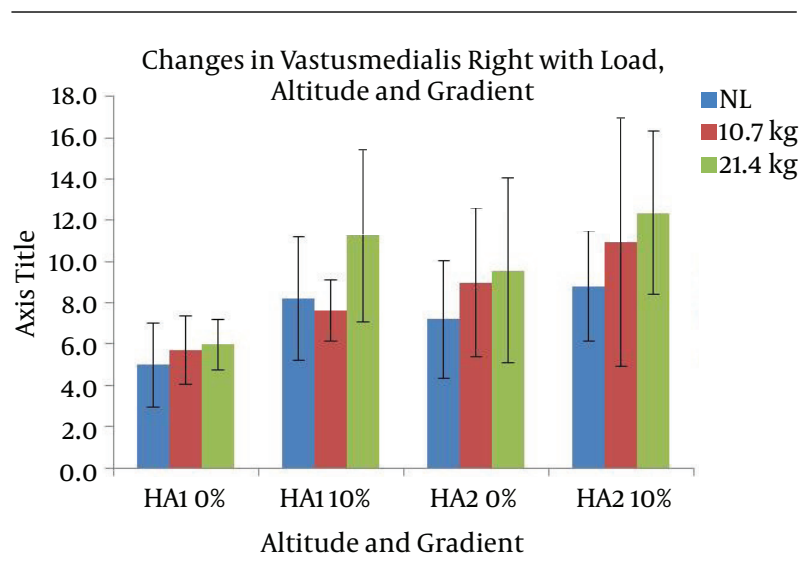

Figure 7. Changes in Activity of Vastusmedialis Right with Altitude, Load, and Gradient

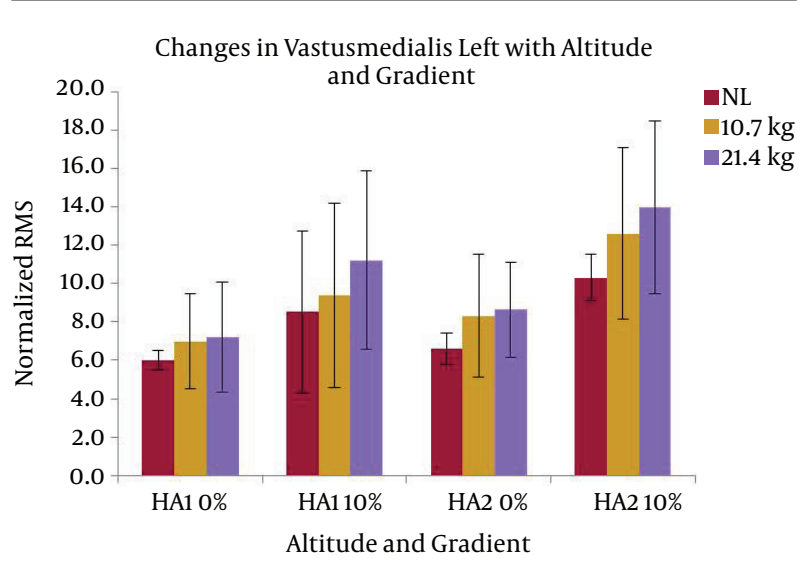

Figure 8. Changes in Activity of Vastusmedialis Left with Altitude, Load, and Gradient

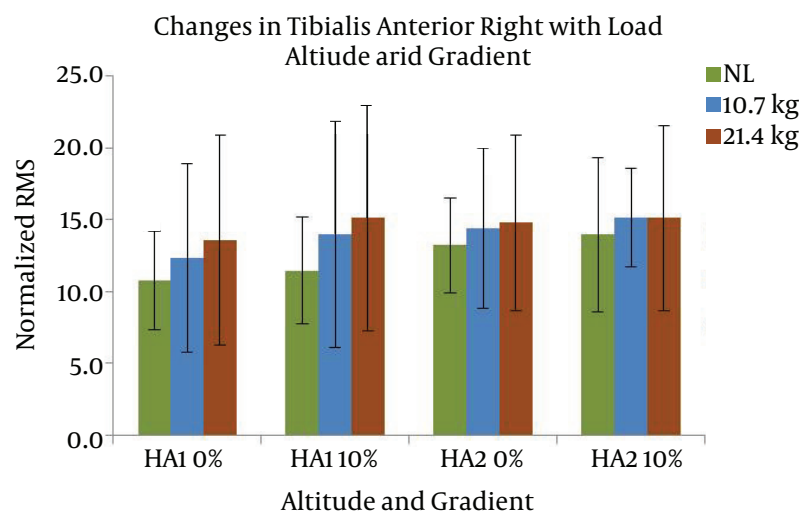

Figure 9. Changes in Activity of Tebialis Anterior Right with Altitude, Load, and Gradient 


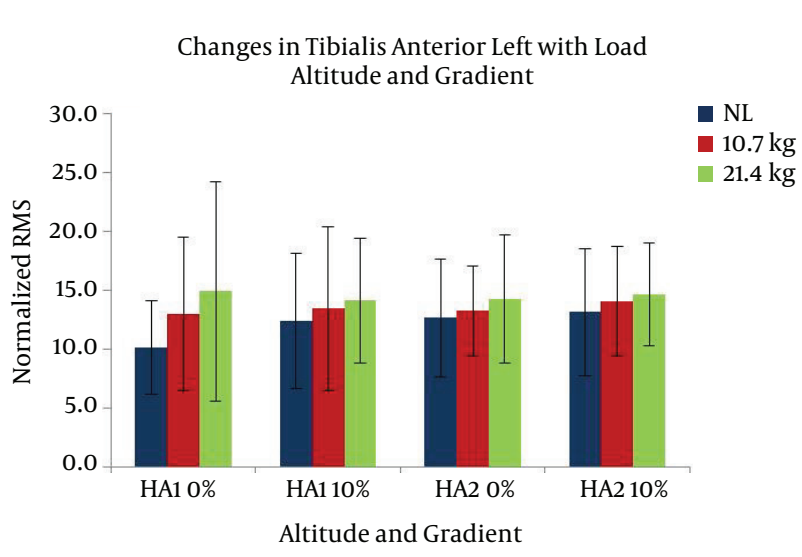

Figure 10. Changes in Activity of Tebialis Anterior Left with Altitude, Load, and Gradient

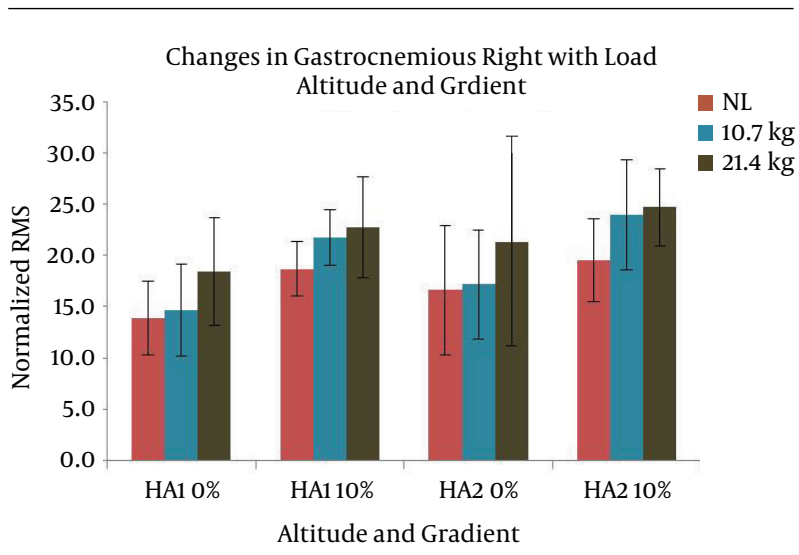

Figure 11. Changes in Activity of Gastrocnemius Right with Altitude, Load, and Gradient

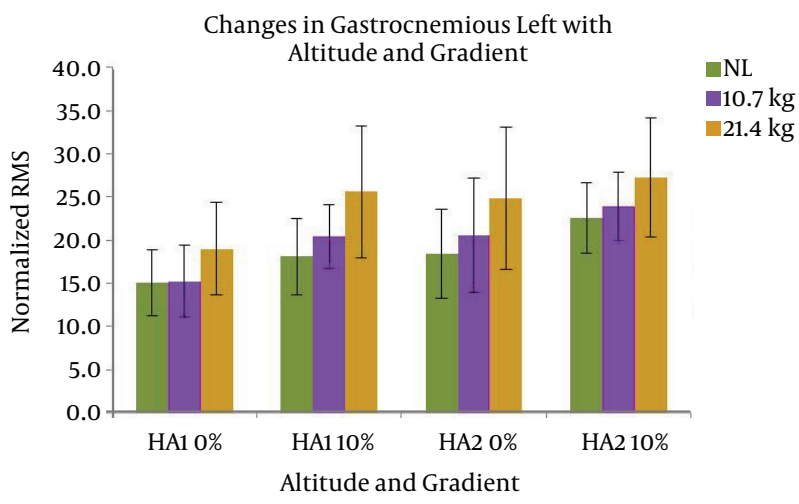

Figure 12. Changes in Activity of Gastrocnemius Left with Altitude, Load, and Gradient white fibers were the reason behind the rise of $\mathrm{VO}_{2}$ according to the authors. They also mentioned that the porters' inability to continue large amount of work at HA may have played a role in preventing overexertion at HA. The findings of the present study completely corroborated with the observations of Nag et al. (1978) (18).

In the present study, the soldiers rated their perceived exertion level as ' 16 ' while carrying L2 at 10\% gradient at HA2, which came between 'hard' and 'very hard' according to RPE table (21). On the other hand, corresponding HR and $\mathrm{VO}_{2}$ were 126.7 b.min ${ }^{-1}$ and $21.5 \mathrm{~mL} \cdot \mathrm{min}^{-1} . \mathrm{kg}^{-1}$, respectively. Such a response was not as intense or equivalent for the same load carriage manoeuvre. Possibly, the local (musculoskeletal) factor during load carriage overwhelmed the overall perception of exertion (33). Researchers have previously pointed the role of cardiopulmonary, central, and local muscular sensations as important factors behind elevated RPE (34-36). Earlier studies also claim that RWL, HR, and $\mathrm{VO}_{2}$ contribute to the central component of the perception of exertion $(34,37)$. The present study was carried out at HA. It can be expected that there was a miss match between the cardio-respiratory responses of the individuals and their perception of exertion during load carriage as an effort to cope up with the physical demands of carrying the same magnitude of load at HA. The role of local components in higher RPE in the present study can be revealed with evaluation of the activities of leg muscles during the same task.

The present study dealt with the analysis of three pairs of lower limb muscles to assess their activity with a combination of different loads, gradients, and altitudes. These muscles were affected by load and gradient in their respective activities. Vastus medialis is a part of quadriceps involved in knee extension (38). Gastrocnemius is a form of calf muscle involved in plantar flexion. Tibialis anterior as the most medial muscle of the anterior compartment of leg is responsible for dorsi-flexion and inverting the foot. The activity of these muscles has been widely studied using EMG (39-41). Franz and Kram (2012) (42) found the effect of grade and speed on hip, knee, and ankle extensor muscles with increased activation while walking uphill $\left(9^{\circ}\right)$. Patla (1986) (43) studied the effect of walking at various elevations on the EMG responses of selected lower limb muscles. Their findings showed that proximal muscles had a greater increase in muscle activation than distal muscles to cope up with the demands imposed by various inclines. Hill walking elicits modifications in muscle activation patterns to meet changes in anterior-posterior stability and propulsion requirements $(44,45)$. Such excessive activity of the soldiers' leg muscles in the present study can be attributed to stabilized extra postural load of inclined walking and constant forward movement of the body. Holewijn 
et al. (1990) (46) measured metabolic, cardiovascular, and EMG responses of a treadmill walking task with a combination of multiple loads and speeds and found that loaded walking resulted in increased $\mathrm{HR}, \mathrm{VO}_{2}$, and EMG activities. The soldiers of Indian Army carry the rifle in hand and HS in waist region. VML and GML muscles had a higher response while carrying the heavier load of $21.4 \mathrm{~kg}$ at both HAs and gradients. Heavier backpacks with rifle in right hand may have prompted the left leg muscles to contract at a greater degree to keep the body's balance intact. On the other hand, excessive contraction of the leg muscles seemed to meet the demands of load carriage at inclination and stress of high altitudes.

An increase in EMG activity was more observed at HA2 than HA1 for almost all leg muscles in the present study, though the effect was not statistically significant. This observation is in agreement with the findings of Orizio et al. (1993) (13), Esposito et al. (2003) (14), and Caquelard et al. (2000) (15) who found the minimum effect of hypoxia in muscular performances. Number of isometric contractions of biceps brachii muscles at HA was assessed by Casale et al. (1999) (47). There was barely a change in the global EMG spectral, amplitude parameters, and conduction velocity during the ten days stay at HA for either voluntary or electrically elicited contractions. These facts intensify the findings of the present study indicating that leg muscles likewise are not considerably affected by HA hypoxia. The soldiers in the present study did not perform sustained contraction; instead they walked on treadmill while carrying load. Human gait cycle is divided into swing phase and stance phase. During normal walking, these phases interchange within each other, and double support phase occurs during the overlap between stance phases of the left and right feet $(48,49)$. Such phasic contractions of lower limb muscles have been tested in plains; but at high altitude, it is less explored. Thus, slightly higher rate of muscular contraction at HA2 can be credited to withstand the stress of load carriage at such an extreme condition and localised exertion.

Vogel et al. (1980) (50) recommended acceptable workload (AWL) for U.S. Army soldiers in outdoor work. According to their suggestion, soldiers could work at a rate of $50 \%$ of $\mathrm{VO}_{2 \max }$ for $8 \mathrm{hrs}$ and $50 \%-75 \%$ of $\mathrm{VO}_{2 \max }$ for 2 hrs. Indian soldiers in the present study had mean RWL of $44.6 \%$, $51.5 \%$, and $55.8 \%$ for carriages of NL, L1, and L2, respectively, at $3.5 \mathrm{~km} . \mathrm{hr}^{-1}$ and $10 \%$ gradient at HA2. The soldiers had an RWL of 35\% for L2 during level ground walking at the same speed and altitude. The participants rated their exertion as '16' with this load, gradient, and altitude combination. Hence, load carriage up to $32 \%$ of body weight (BW, L2) is suggested for 2 hrs at $4300 \mathrm{~m}$ height, $3.5 \mathrm{~km} . \mathrm{hr}^{-1}$ walking speed, and 10\% gradient. Alower magnitude of load, i.e. $16 \%$ of BW, is suggested to be carried for up to $8 \mathrm{hr}$ in this combination of height, speed, and gradient. The RWL for HA1 at same speed and gradient was $27.3 \%, 36.4 \%$, and $47.5 \%$ in NL, L1, and L2, respectively. In these conditions, the soldiers' perceived exertion was ' 15 ', i.e. 'hard', for L2. Hence, at 3500 $\mathrm{m}$ height, a load up to $32 \%$ of BW is recommended for carriage for 8 hrs with gradient of $10 \%$ at speed not exceeded $3.5 \mathrm{~km} . \mathrm{hr}^{-1}$. At level ground walking, maximum RWL at HA1 was $24.5 \%$ of $\mathrm{VO}_{2 \max }$. In this context, $32 \%$ of $\mathrm{BW}$ is recommended for carriage for longer duration such as $8 \mathrm{hrs}$ at 3500 and $4300 \mathrm{~m}$ height, $0 \%$ gradient, and $3.5 \mathrm{~km} . \mathrm{hr}^{-1}$ walking speed.

\subsection{Study Limitations}

The suggestions presented above are based on load carriage study at level ground and $10 \%$ gradient at two high altitudes. The effect of texture of the terrain, wind chill, snow, and steeper gradients etc. was excluded from the findings of the study. All the participants were on the way of their respective HA posting. Thus, due to limited time, data of load carriage task of similar intensity at sea level could not be recorded.

\subsection{Conclusions}

Load carriage with existing LCe at $3550 \mathrm{~m}$ and $4300 \mathrm{~m}$ heights with a speed of $3.5 \mathrm{~km} . \mathrm{hr}^{-1}$ and $10 \%$ gradient resulted in a significant rise in $\mathrm{HR}, \mathrm{VO}_{2}$ and RWL and RPE scores. The HR and RPE changed significantly with load and gradient. Significant activation of VMR, VML, GMR, and GML muscles were observed in response to increasing gradient and load. The activities in TAL changed only with load. There were little increase in activities of VMR, VML, GMR, and GML accompanied by increase in altitude. Slightly increased muscular activity of lower limbs could sustain the requirement of load carriage task in inclination of the treadmill and can be extrapolated to steep slopes of high mountains. Depending on the RWL and RPE at $3550 \mathrm{~m}$ height, a load up to $32 \%$ of BW is recommended for carriage for 8 hrs with gradient of $10 \%$ at speed not exceeded $3.5 \mathrm{~km} \cdot \mathrm{hr}^{-1}$. A load up to $32 \%$ of BW is suggested for carriage for 2 hrs at $4300 \mathrm{~m}$ height, $3.5 \mathrm{~km} . \mathrm{hr}^{-1}$ walking speed, and $10 \%$ gradient. The findings of the study will be useful in designing load carriage task at various HAs and will be helpful in assessing injury proneness and prevention. The suggestions are applicable to the global soldier community and other civilians who regularly operate in HA terrain conditions.

\section{Acknowledgments}

The data collected under the present study were obtained thanks to sincere participation of soldiers work- 
ing at high altitude with its challenging environmental vagaries. The authors also thank all the commanding officers and other ranks of respective army units for their wholehearted cooperation and logistical support.

\section{Footnotes}

Authors' Contribution: Tirthankar Chatterjee involved in study design, data collection, analysis, interpretation, manuscript writing etc; Debojyoti Bhattacharyya involved in data collection, analysis, manuscript writing; Anilendu Pramanik involved in data collection, analysis; Madhu Sudan Pal involved in overall supervision, data collection; Dhurjati Majumdar involved in data collection, interpretation; Dhurjati Majumdar involved in study design, guidance, manuscript writing.

Financial Disclosure: The authors declare that there is no financial conflict and no competing interest for future.

Funding/Support: All sources of the study including the design, data collection, analysis, and interpretation and writing the manuscript were funded through project No. S\&T-09/DIP-251, C3.0 from the defence research and development organization (DRDO), ministry of defence, government of India. Defence Research and Development Organization (DRDO), Ministry of Defence, Government of India has funded the project, which was closed on 2015.

\section{References}

1. Minetti AE, Formenti F, Ardigo LP. Himalayan porter's specialization: metabolic power, economy, efficiency and skill. Proc Biol Sci. 2006;273(1602):2791-7. doi: 10.1098/rspb.2006.3653. [PubMed: 17015318].

2. Majumdar D, Pal MS, Majumdar D. Effects of military load carriage on kinematics of gait. Ergonomics. 2010;53(6):782-91. doi: 10.1080/00140131003672015. [PubMed: 20496244].

3. Chatterjee T, Bhattacharyya D, Pal M, Majumdar D. Cardiorespiratory changes with compact backpack system and distributed mode of load carriage. Indian J Physiol Pharmacol. 2012;56(2):130-6. [PubMed: 23387241].

4. Harman E, Han KH, Frykman P. Load-speed interaction effects on the biomechanics of backpack load carriage. Soldier Mobility: Innovations in Load Carriage System Design and Evaluation. 2000; Kingston, Canada. .

5. Quesada PM, Mengelkoch LJ, Hale RC, Simon SR. Biomechanical and metabolic effects of varying backpack loading on simulated marching. Ergonomics. 2000;43(3):293-309. doi: 10.1080/001401300184413. [PubMed: 10755654].

6. Knapik JJ, Reynolds KL, Harman E. Soldier load carriage: historical, physiological, biomechanical, and medical aspects. Mil Med. 2004;169(1):45-56. [PubMed: 14964502].

7. van Dijk J. Common Military Task: Marching. In: The Research and Technology Organisation (RTO), editor. Optimizing Operational Physical Fitness. ; 2009. .

8. Pope RP. Prevention of pelvic stress fractures in female army recruits. Mil Med. 1999;164(5):370-3. [PubMed: 10332180].
9. Liu MM, Herzog W, Savelberg HH. Dynamic muscle force predictions from EMG: an artificial neural network approach. J Electromyogr Kinesiol. 1999;9(6):391-400. [PubMed: 10597052].

10. Alkner BA, Tesch PA, Berg HE. Quadriceps EMG/force relationship in knee extension and leg press. Med Sci Sports Exerc. 2000;32(2):459-63. [PubMed: 10694132].

11. Ghori GM, Luckwill RG. Responses of the lower limb to load carrying in walking man. EurJAppl Physiol Occup Physiol. 1985;54(2):145-50. [PubMed: 4043040].

12. Perrey S, Rupp T. Altitude-induced changes in muscle contractile properties. High Alt Med Biol. 2009;10(2):175-82. doi: 10.1089/ham.2008.1093. [PubMed: 19519224].

13. Orizio C, Esposito F, Veicsteinas A. Effect of acclimatization to high altitude $(5,050 \mathrm{~m})$ on motor unit activation pattern and muscle performance. J Appl Physiol (1985). 1994;77(6):2840-4. [PubMed: 7896630].

14. Esposito F, Orizio C, Parrinello G, Veicsteinas A. Chronic hypobaric hypoxia does not affect electro-mechanical muscle activities during sustained maximal isometric contractions. EurJ Appl Physiol. 2003;90(34):337-43. doi: 10.1007/s00421-003-0922-3. [PubMed: 12937990].

15. Caquelard F, Burnet H, Tagliarini F, Cauchy E, Richalet JP, Jammes Y. Effects of prolonged hypobaric hypoxia on human skeletal muscle function and electromyographic events. Clin Sci (Lond). 2000;98(3):329-37. [PubMed: 10677392].

16. Chatterjee T, Bhattacharyya D, Pramanik A, Pal M, Majumdar D, Majumdar D. Soldiers' load carriage performance in high mountains: a physiological study. Mil Med Res. 2017;4(1) doi: 10.1186/s40779-017-0113$\mathrm{x}$.

17. Pal MS, Majumdar D, Bhattacharyya M, Kumar R, Majumdar D. Optimum load for carriage by soldiers at two walking speeds on level ground. Int J Industr Ergon. 2009;39(1):68-72. doi: 10.1016/j.ergon.2008.05.002.

18. Nag PK, Sen RN, Ray US. Optimal rate of work for mountaineers. Appl Physiol Respir Environ Exerc Physiol. 1978;44(6):952-5. [PubMed: 670016].

19. Wasserman K, Hansen JE, Sue DY, Whipp BJ, Froelicher VF. Principles of exercise testing and interpretation.J Cardiopulmon Rehabil Prevent. 1987;7(4):189.

20. Macfarlane DJ, Wong P. Validity, reliability and stability of the portable Cortex Metamax 3B gas analysis system. Eur J Appl Physiol. 2012;112(7):2539-47. doi: 10.1007/s00421-011-2230-7. [PubMed: 22075643].

21. Borg G. Perceived exertion as an indicator of somatic stress. Scand J Rehabil Med. 1970;2(2):92-8. [PubMed: 5523831].

22. Hardie R, Haskew R, Harris J, Hughes G. The effects of bag style on muscle activity of the trapezius, erector spinae and latissimus dorsi during walking in female university students.J Hum Kinet. 2015;45:39-47. doi: 10.1515/hukin-2015-0005. [PubMed: 25964808].

23. Harman E, Han KH, Frykman P. Load-speed interaction effects on the biomechanics of backpack load carriage. DTIC Document; 2001.

24. Hermens HJ, Freriks B, Disselhorst-Klug C, Rau G. Development of recommendations for SEMG sensors and sensor placement procedures. JElectromyogr Kinesiol. 2000;10(5):361-74. [PubMed: 11018445].

25. Bosco C, Viitasalo JT. Potentiation of myoelectrical activity of human muscles in vertical jumps. Electromyogr Clin Neurophysiol. 1982;22(7):549-62. [PubMed: 7151734].

26. Fauth ML, Petushek EJ, Feldmann CR, Hsu BE, Garceau LR, Lutsch $\mathrm{BN}$, et al. Reliability of surface electromyography during maximal voluntary isometric contractions, jump landings, and cutting. $J$ Strength Cond Res. 2010;24(4):1131-7. doi: 10.1519/JSC.0b013e3181cc2353. [PubMed: 20179648].

27. Arsenault AB, Winter DA, Marteniuk RG, Hayes KC. How many strides are required for the analysis of electromyographic data in gait?. Scand J Rehabil Med. 1986;18(3):133-5. [PubMed: 3787209].

28. Neumann DA, Cook TM. Effect of load and carrying position on the electromyographic activity of the gluteus medius muscle during walking. Phys Ther. 1985;65(3):305-11. [PubMed: 3975279]. 
29. Yang JF, Winter DA. Electromyographic amplitude normalization methods: improving their sensitivity as diagnostic tools in gait analysis. Arch Phys Med Rehabil. 1984;65(9):517-21.

30. Minetti AE, Moia C, Roi GS, Susta D, Ferretti G. Energy cost of walking and running at extreme uphill and downhill slopes. J Appl Physiol (1985). 2002;93(3):1039-46. doi: 10.1152/japplphysiol.01177.2001. [PubMed: 12183501].

31. Crouter S, Foster C, Esten P, Brice G, Porcari JP. Comparison of incremental treadmill exercise and free range running. Med Sci Sports Exerc. 2001;33(4):644-7. [PubMed: 11283442].

32. Padulo J, Powell D, Milia R, Ardigo LP. A paradigm of uphill running. PLoS One. 2013;8(7):ee69006. doi: 10.1371/journal.pone.0069006. [PubMed: 23874850].

33. Goslin BR, Rorke SC. The perception of exertion during load carriage. Ergonomics. 1986;29(5):677-86. doi: 10.1080/00140138608968302. [PubMed: 3720724].

34. Kinsman RA, Weiser PC. Subjective symptomatology during work and fatigue. In: Simonson E, Weiser PC, editors. Psychological aspects and physiological correlates of work and fatigue. Springfield: Charles Thomas; 1976. pp. 336-405.

35. Pandolf KB, Burse RL, Goldman RF. Differentiated ratings of perceived exertion during physical conditioning of older individuals using leg-weight loading. Percept Mot Skills. 1975;40(2):563-74. doi 10.2466/pms.1975.40.2.563. [PubMed: 1178328].

36. Cafarelli E, Cain WS, Stevens JC. Effort of dynamic exercise: influence of load, duration, and task. Ergonomics. 1977;20(2):147-58. doi: 10.1080/00140137708931613. [PubMed: 858300].

37. Pandolf KB. Influence of local and central factors in dominating rated perceived exertion during physical work. Percept Mot Skills. 1978;46(3 Pt 1):683-98. doi:10.2466/pms.1978.46.3.683. [PubMed: 673625].

38. Ericson MO, Nisell R, Ekholm J. Quantified electromyography of lower-limb muscles during level walking. Scand J Rehabil Med. 1986;18(4):159-63. [PubMed: 3810082].

39. Solomonow M, Baratta RV,Zhou BH, Burger E, Zieske A, Gedalia A. Mus- cular dysfunction elicited by creep of lumbar viscoelastic tissue. JElectromyogr Kinesiol. 2003;13(4):381-96. [PubMed: 12832168].

40. Kellis E, Katis A. Hamstring antagonist moment estimation using clinically applicable models: Muscle dependency and synergy effects. J Electromyogr Kinesiol. 2008;18(1):144-53. doi: 10.1016/j.jelekin.2006.09.001. [PubMed: 17055745].

41. Marson R, Goncalves M. Comportamento eletromiografico do musculo biceps femoris (caput longum) submetido a exercicio isometrico. In: Marson R, Goncalves M, editors. Anais do IX Congresso Brasileiro de Biomecanica. Brazil: Gramado; 2001. pp. 289-93.

42. Franz JR, Kram R. The effects of grade and speed on leg muscle activations during walking. Gait Posture. 2012;35(1):143-7. doi: 10.1016/j.gaitpost.2011.08.025. [PubMed: 21962846].

43. Patla AE. Effects of walking on various inclines on EMG patterns of lower limb muscles in humans. Human Mov Sci. 1986;5(4):345-57. doi: 10.1016/0167-9457(86)90013-8.

44. Tokuhiro A, Nagashima $\mathrm{H}$, Takechi H. Electromyographic kinesiology of lower extremity muscles during slope walking. Arch Phys Med Rehabil. 1985;66(9):610-3. [PubMed: 4038027].

45. Earhart GM, Bastian AJ. Form switching during human locomotion: traversing wedges in a single step. J Neurophysiol. 2000;84(2):605-15. [PubMed: 10938289].

46. Holewijn M. Physiological strain due to load carrying. Eur J Appl Physiol Occup Physiol. 1990;61(3-4):237-45. doi:10.1007/bfo0357606.

47. Casale R, Farina D, Merletti R, Rainoldi A. Central and peripheral muscle fatigue in hypobaric and hypoxic conditions 2012. Available from: http://www.lisin.polito.it/english/annual_reports/ar1999_uk/ 42uk.htm.

48. Perry J, Davids JR. Gait analysis: normal and pathological function.J Pediatr Orthopaed. 1992;12(6):815.

49. Rose J, Gamble JG. Human walking. Williams and Wilkins; 1994.

50. Vogel JA, Wright JE, Patton III JF. Development of New Gender-Free Physical Fitness Standards for the Army. DTIC Document; 1980. 